Tielens, P., De Rijcke, S., Srivastava, K., Muhamad, R., Antonis, M., Driesen, J. (2012). Frequency Support by Wind Power Plants in Isolated Grids with Varying Generation Mix. . IEEE Power and Energy Society General Meeting 2012. San Diego, USA, 22-26 July 2012.

Digital Object Identifier: 10.1109/PESGM.2012.6344690

URL:

http://ieeexplore. ieee . org/stamp/stamp. jsp?tp=\&arnumber $=6344690$

(C)2012 IEEE. Personal use of this material is permitted. Permission from IEEE must be obtained for all other users, including reprinting/ republishing this material for advertising or promotional purposes, creating new collective works for resale or redistribution to servers or lists, or reuse of any copyrighted components of this work in other works. 


\title{
Frequency Support by Wind Power Plants in Isolated Grids with Varying Generation Mix
}

\author{
Pieter Tielens, Student Member, IEEE, Simon De Rijcke, Student Member, IEEE, Kailash Srivastava, Member, \\ IEEE, Muhamad Reza, Member, IEEE, Antonis Marinopoulos, Member, IEEE, Johan Driesen, Member, IEEE
}

\begin{abstract}
Increasing wind power penetration in power systems has resulted in an urgent need for the assessment of their impact on grid security. Besides the participation in voltage control, there also exists a growing interest in the delivering of other ancillary services like power-frequency control. This paper investigates further the technical feasibility of delivering frequency support with wind turbines in a small power system. Different control mechanisms are elaborated in Matlab/Simulink to deliver frequency support in the case where the turbines have a power reserve available and in the case where they are operating at maximum available power. Also the influence of the generation mix is examined. Results reveal that the displacement of conventional generation with wind power results in a deterioration of the frequency response. However, due to the implementation of the different control mechanisms presented in this paper for delivering inertial response and primary control, the frequency stability is improved.
\end{abstract}

Index Terms-power-frequency control, wind power penetration, wind turbine control.

\section{INTRODUCTION}

A $\mathrm{T}$ the start of 2011, after a decade of significant growth, the installed wind power reached a global capacity of 195 GW [1]. Continuous progress in technology and the relatively low capital costs compared to other forms of renewable energy are all motivating factors for this upward trend. Together with the increase in capacity, many countries cope with high levels of wind power penetration. In the pioneer countries, as for instance Denmark and Spain, instantaneous wind power penetration of over $45 \%$ has already been reported [2]. It is thus clear that wind power becomes a major component in electricity generation and, taking into account its specific characteristics, is expected to have a large influence on the security and quality of power supply.

One of the crucial aspects of the power system stability is the instantaneous active power balance, which is maintained by the frequency control. This refers to the ability of the power system to stabilize and restore the system frequency after a significant imbalance between generation and load. Otherwise, large variations in frequency can cause grid instability and load shedding, which may degenerate into a blackout. The frequency response directly after the imbalance is determined by the inertia of the system and the primary control action of the generators.

P. Tielens, S. De Rijcke and J. Driesen are with the ELECTA research group, Electrical Engineering Department ESAT, Kasteelpark Arenberg 10, 3001 Heverlee, Belgium, email: pieter.tielens@esat.kuleuven.be

K. Srivastava, M. Reza and A. Marinopoulos are with ABB Corporate Research, 72178 Västerås, Sweden
Modern wind turbines are equipped with power electronic converters, decoupling the generator from the grid. Therefore, wind turbine generators deliver no inertial response and the system inertia decreases if conventional generation is replaced by wind. Consequently, higher rates of frequency changes are observed after various system contingencies or sudden load variations. Active governors have less time to react, resulting in larger frequency deviations.

Regarding primary control, wind turbines are generally required to remain connected during frequency variations while they are exempt from delivering any form of frequency control. In the future however, it is expected that they also contribute to the primary control by adjusting their active power output after a frequency event. This is likely to become a vital feature of wind turbines in island systems, whose inertia is lower compared to large interconnected grids where major frequency variations often result in load shedding.

The paper is organized as follows. Section II of this paper describes the different test cases that are used throughout the simulations. The next section, III, describes further the inertial response of wind turbines and their kinetic energy storage. Section IV, gives an overview of a simplified power-frequency model of a power system and the control of the wind turbine with the different types of frequency controllers. Next, in section $\mathrm{V}$, the results of the different simulations are discribed. The influence of the generation mix is further elaborated in section VI. Finally, section VII resumes the main conclusions and provides some recommendations for future research.

\section{APPROACH AND METHODOLOGY}

In order to evaluate the frequency support by wind turbines, a small isolated power sytem is used as a test grid. The power system consists of three steam turbines (ST), one hydraulic turbine (HT), one gas turbine (GT) and a wind power plant equipped with doubly fed induction generators (DFIG) as shown in Figure 1, with the capacity of each generator in parentheses. Both a frequency dip and a frequency surge are simulated, by respectively tripping the gas turbine and lowering the load with $50 \mathrm{MW}$. The inertia constant, dispatched power and droop settings for each power plant are given in Appendix A.

Different cases are considered. In case A, the wind power plant produces no power, the total power of $500 \mathrm{MW}$ is supplied by the other power plants. In case B, the wind turbines produce $100 \mathrm{MW}$. To balance generation and consumption, the first steam turbine is shut down. Economic considerations are not taken into account. Next, the wind turbines are equipped 


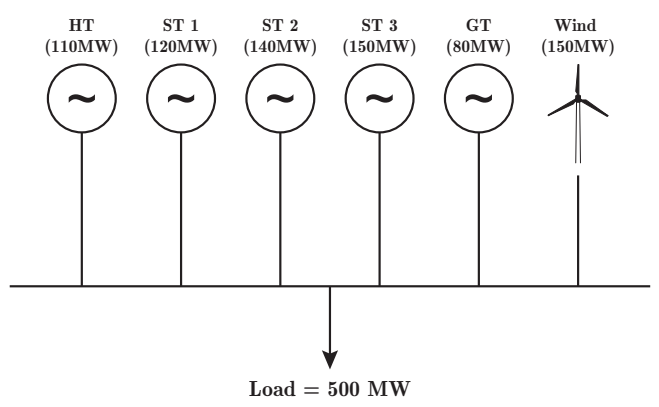

Fig. 1. Power system used in simulations

with a frequency controller that reacts to a frequency change by decreasing or increasing the power output. The control mechanisms can be split up into two main groups: frequency control in optimal operating point (case C \& D) and frequency control in sub-optimal operating point (case E). In the first group, the wind turbines operate at optimal operating point without having any reserve power. When a frequency dip/surge arises, the turbine is able to deliver inertial response and primary control, by interchanging its stored kinetic energy with the grid. In the second group, the wind turbines are deloaded to have a power reserve available to deliver frequency support. Finally, also the influence of the generation mix is further investigated.

Before describing the control models in more detail, the inertial response and the kinetic energy storage of a wind turbine are elaborated in the next section.

\section{ASSESSMENT OF PRIMARY RESERVES BY WIND TURBINES}

\section{A. Inertial response of wind turbine generators}

The inertial response of wind turbine generators differs from the synchronous generators used in conventional power plants. Because the synchronous generator rotates synchronously with the grid frequency, the generator will immediately inject kinetic energy into the grid and thus deliver a large inertial response.

Fixed speed wind turbines with squirrel cage induction generators (SCIG) will also react to frequency changes, however with a smaller and delayed inertial response. As illustrated in Figure 2, the torque-speed curve of an induction generator moves to the left when the frequency drops. If the speed of the generator initially remains constant, the torque as well as the power is raised. The operating point will move from number one to two. Assuming that the wind speed, and hence the mechanical power input is constant, the machine will inject his kinetic energy in the grid and slow down [3].

Variable speed wind turbines on the other hand are equipped with back-to-back converters, which electrically decouples partly or fully the generator from the grid. Due to this decoupling and fast power control, the generator will not respond to a frequency change and the output power is kept constant during a frequency event. No inertial response is delivered.

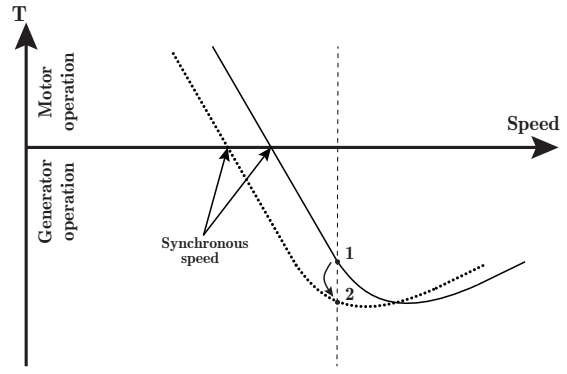

Fig. 2. Torque-speed curve of an induction generator

\section{B. Kinetic energy storage in wind turbines}

Although variable speed wind turbines do not contribute to the system inertia, they store a significant amount of kinetic energy. Both the rotor blades and the generator contribute to the stored energy. Even though the rotational speed of the generator is 80 - 100 times higher than the rotor blades when a gearbox is present, most of the kinetic energy is coming from the rotor blades due to their high inertia [4]. The inertia of the blades can be expressed in function of the rated power [5]:

$$
J_{\text {blades }}=1.74 \times 10^{-7} P_{\text {rated }}^{2.13}
$$

According to this equation, the rotor blades of a $2 \mathrm{MW}$ variable speed wind turbine for example, have an inertia of approximately $4.510^{6} \mathrm{kgm}^{2}$. With a nominal speed of 1.8 $\mathrm{rad} / \mathrm{s}$, the kinetic energy is about 7.4 MJ. The stored kinetic energy in the generator, with a nominal speed of $104 \mathrm{rad} / \mathrm{s}$ and an inertia of $200 \mathrm{kgm}^{2}$, is $2 \mathrm{MJ}$. The total kinetic energy that is stored is thus $9.4 \mathrm{MJ}$ and the inertia constant $4.7 \mathrm{~s}$. This is comparable to the inertia constants of conventional power plants.

Several other aspects should be mentioned when comparing the kinetic energy of conventional power plants and modern variable speed wind turbines:

- The stored kinetic energy in a generator of a conventional power plant is always the same, because they rotate synchronously with the system frequency. The stored kinetic energy of a variable speed wind turbine on the other hand varies because of their changing rotor speed.

- In case of a frequency dip, synchronous generators will slow down according to the system frequency. The injected kinetic energy into the grid will only be a small fraction of the total stored kinetic energy. For a wind turbine, the decoupling and different controllers allow the managing of the rotational speed. The energy release can be controlled independent of the variations of the system frequency.

- The disadvantage of using wind turbines to contribute to inertial response is the variability of the primary energy source, the wind. The stored kinetic energy depends on the wind speed. Hence, if the wind speed is low, the possibilities of injecting kinetic energy in the grid are limited. If the rotor slows down, stalling of the turbine must also be prevented [6]. 


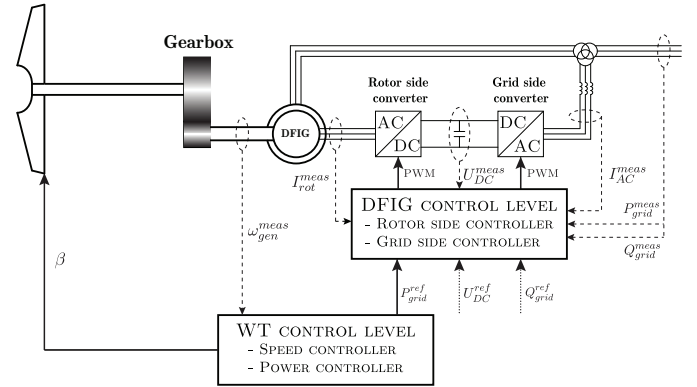

Fig. 3. Variable speed wind turbine with DFIG: the solid lines reveal the controller outputs, the dashed lines denote the measured variables and the dotted lines indicate the set point signals

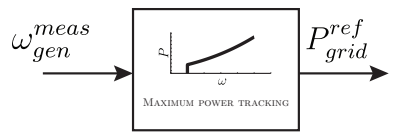

(a) Power control

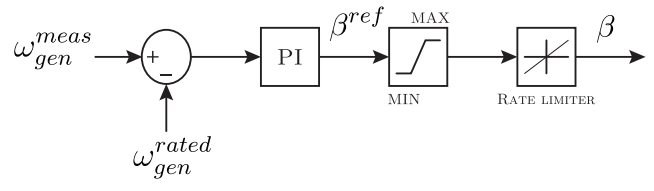

(b) Speed control

Fig. 4. WT control level

\section{MODELING AND CONTROL}

\section{A. Wind turbine model}

This work focuses mainly on the variable speed wind turbine equipped with a DFIG, which is currently the most used topology in Europe [1]. The general scheme of the DFIG, converters and controllers is displayed in Figure 3. A full description of the modeling and control of the DFIG is given in [7], [8]. To control the wind turbine, two control levels can be distinguished [8]. The upper wind turbine control level controls the rotor speed and the reference active power, see Figure 4. The reference value is derived from the Maximum Power Tracking (MPT)-curve, which describes the optimal operation points of turbine (power in function of rotor speed). It should be mentioned that the active power reference can also be imposed externally, e.g. by the grid operator. The pitch system will increase the pitch angle in the high wind speed region to limit the generator speed to its maximum value The lower DFIG control level ensures the electrical control of the back-to-back converter. The rotor-side converter controller controls independently the active and the reactive power. The grid-side converter controller controls the DC-voltage of the converter and guarantees a unity power factor between the converter and the grid.

\section{B. Grid model}

To simulate the frequency response in a power system, an equivalent power-frequency model as shown in Figure 5 is developed. In this model, intermachine-oscillations and performance of the transmission system are not considered. Taking

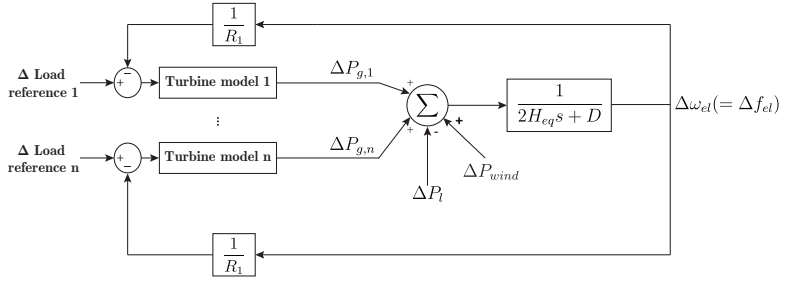

Fig. 5. Power-frequency model

into account these simplifications, the response of all the generators in a grid to changes in system load and generation can be represented by the response of one equivalent generator [9]. The inertia constant of this generator equals to the sum of the inertia constants of all the operating generators in the grid [10], [11]:

$$
H_{e q}=\sum H_{i} \frac{S_{i}}{S_{s y s}}
$$

with $S_{\text {sys }}$ the system base power, $H_{i}$ the inertia constant and $S_{i}$ the apparent power of a single generator. In a similar way, the effect of the frequency dependent loads are represented by a single load with damping constant $\mathrm{D}$. The input power of the equivalent generator is the sum of the output powers of all the generators and the consumed power. The relation between the changes in load, generation and system frequency can therefore be written in the Laplace domain as [9]:

$$
\frac{\Delta P_{g}-\Delta P_{l}}{2 H_{e q} s+D}=\Delta \omega_{e l}
$$

with s the Laplace operator. $\omega_{e l}$ is equal to the speed of the synchronous generator and the system frequency. Each power plant is also equipped with a governor with droop constant $\mathrm{R}$ to simulate the primary control action of the system.

\section{Frequency support by wind turbines in optimal operating point}

Wind turbines are currently set to maximize their power output under all circumstances. Hence, they have no upward power margin available to deliver primary control like some conventional power plants do. However, due to their large amount of kinetic energy and high control flexibility, the turbine can be controlled to deliver inertial response and primary control for a short period. It should be noted that the control mechanisms presented in this section cannot be applied to fixed speed wind turbines because they cannot vary their rotor speed independent of the system frequency. A controlled release of kinetic energy is therefore not possible. Only in variable speed wind turbines, the speed and power can both be managed.

1) Delivering inertial response (Case C): To emulate the inertial response of a synchronous generator, the power controller of the variable speed turbine with DFIG is adapted as shown in Figure 6. This controller will react to the rate of change of frequency. If for instance, the frequency suddenly drops, the controller is activated and delivers an additional 


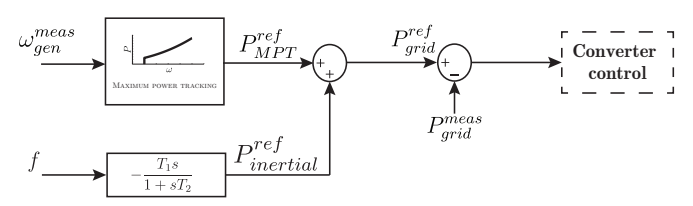

Fig. 6. Inertial response controller

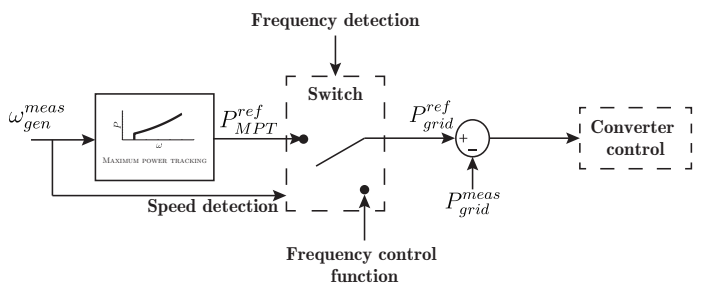

Fig. 7. Frequency support controller: fast release of kinetic energy

power reference value to the converter of the DFIG [12]. This additional power output is a function of the frequency:

$$
P_{\text {inertial }}^{\text {ref }}=-\frac{T_{1} s}{1+s T_{2}} f
$$

with $\mathrm{s}$ the Laplace operator, $f$ the frequency, $T_{1}$ and $T_{2}$ the controller parameters. The denominator of equation 4 is actually a low pass filter. Hence, the controller does not react to small frequency variations.

2) Fast release of kinetic energy (Case D): In the previous section, the control mechanism did not take fully advantage of the electrical decoupling and the fast control action of the converter. Case $\mathrm{C}$ assumes that the variable speed turbine reacts to a frequency disturbance in the same way conventional generators do. However, the power reference can be modified in order to deliver any type of power response during a frequency event [6]. The model proposed in this paper, consists of a frequency support controller that will detect a frequency disturbance (if the frequency is outside a predefined dead band) and takes over the power control. An overview of the model is displayed in Figure 7.

In case of a frequency dip, the frequency controller will send an additional power reference on top of the initial value to use the kinetic energy from the turbine to support the frequency control during a predefined time. The control function that is assigned to the frequency controller is displayed in Figure 8. After $t=t_{d e c}$, the power reference is lowered to accelerate the turbine to return to its optimal operating point. When the rotor speed is back to the pre-disturbance level, the frequency controller is switched off and the turbine continues normal operation.

D. Frequency support by wind turbines in sub-optimal operating point (Case E)

To deliver long-term frequency support, the wind turbines need to reserve a power margin. Starting from the optimal operating point, three main control approaches can be distinguished to deload the wind turbines. The first method (A) consists in varying the pitch angle while keeping the rotor

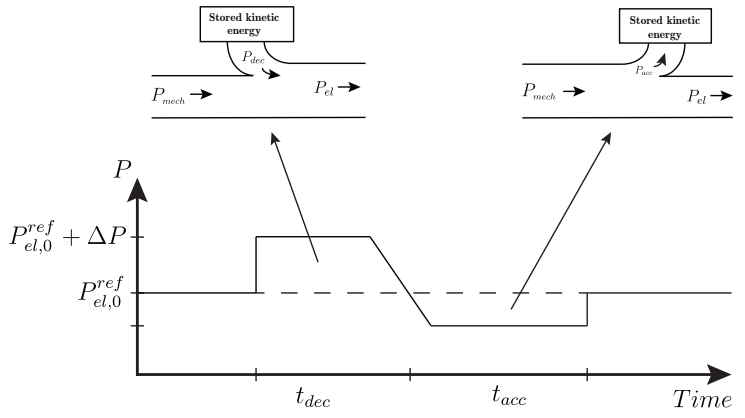

Fig. 8. Frequency control function

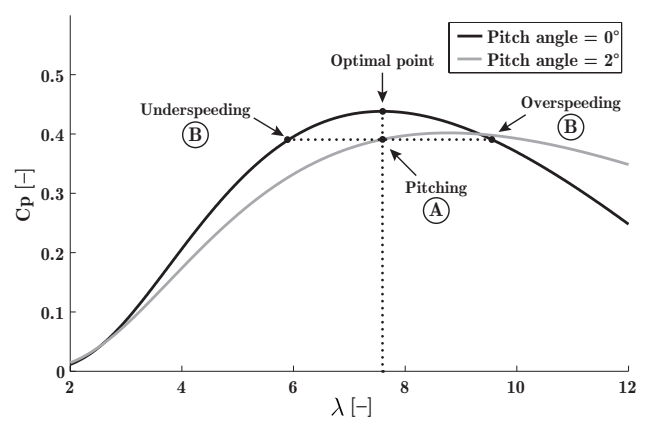

Fig. 9. Deloading wind turbine

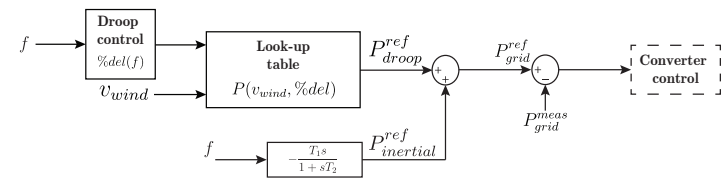

Fig. 10. Delivering primary control and inertial response

speed at its optimal value. A second method (B) uses the rotor speed to create the power reserve (underspeeding or overspeeding). Finally, a third method combines both speed as pitch angle control. The second method with overspeeding is preferable, because overspeeding will increase the kinetic energy storage in the turbine. The different methods are summarized in Figure 9, where the power coefficient $\left(C_{p}\right)$ is shown in function of the tip speed ratio $\left(\lambda=\frac{\omega R}{v}\right)$. The power control of the DFIG is now adjusted to deliver both inertial response and primary control. The controller is shown in Figure 10. It can be split up into two parts.

The first part emulates the droop of a conventional generator. The frequency is measured and is converted into a power reference. At nominal operation, the turbine operates at $80 \%$ of its maximum available power. If the frequency decreases/increases, the power output is increased/decreased. The second part emulates the inertial response of a synchronous generator. It is actually the same controller as described in Figure 6. 

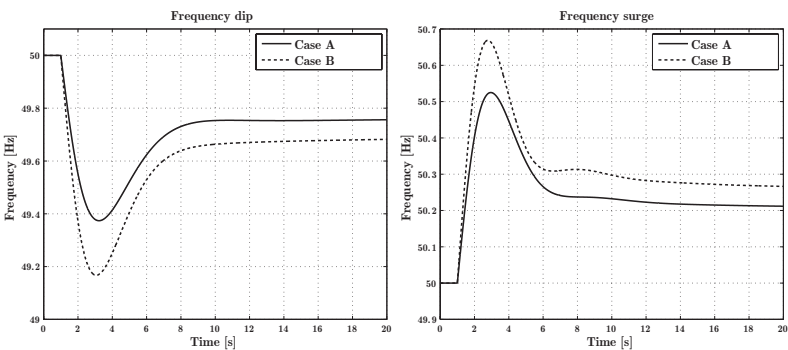

Fig. 11. Frequency response case A \& B

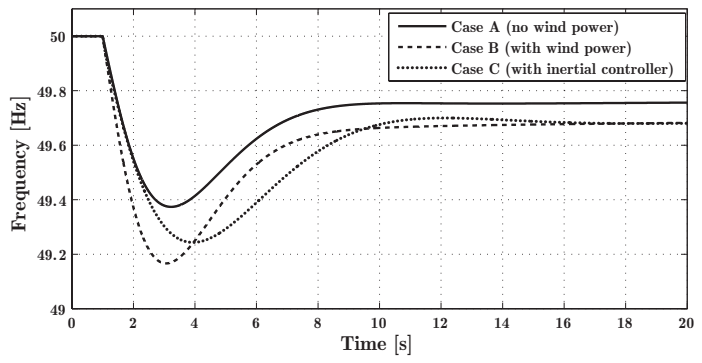

Fig. 12. Frequency response case A,B \& C

\section{RESULTS}

\section{A. Impact of wind power penetration on frequency stability}

The frequency response (dip and surge) of case A and case B are shown in Figure 11. If the turbines replace the conventional power plant, the system inertia and the number of power plants delivering primary control is decreased. This greatly influences the frequency response. Not only the initial rate of change of frequency (ROCOF) is increased, also the minimum/maximum frequency is decreased/increased in the case of a frequency dip/surge. For instance, looking at the frequency dip, the ROCOF is increased from -0.51 to -0.76 and the minimum frequency is decreased from $49.4 \mathrm{~Hz}$ to $49.2 \mathrm{~Hz}$. Especially in small island grids with high wind power penetration, the frequency stability is deteriorated, which may results in load shedding or even a black-out.

\section{B. Frequency support by wind turbines in optimal operating point}

1) Delivering inertial response (Case $C$ ): The frequency response of case A (without wind power), case $\mathrm{B}$ (with wind power, without additional controllers) and case $\mathrm{C}$ where an inertial response controller is integrated in the turbines are compared. The results of a frequency dip are displayed in Figure 12. It shows, that by adding an extra controller, the inertial response of the system is higly improved. During the first seconds after the gas turbine trips, the rate of change of frequency is lower than for case B. The governors of the conventional power plants have more time to react, resulting in a lower minimum frequency. The frequency after $20 \mathrm{~s}$ is however the same as in case $\mathrm{B}$, because the turbine delivers no primary control.
2) Fast release of kinetic energy (Case D): The frequency support controller of section IV-C2 is implemented in the DFIG model and the test grid. The results of the simulation for a frequency dip are shown in Figure 13. When a frequency deviation is detected, the frequency controller will bypass the MPT-controller and the output power is increased step-wise with 0.1 p.u.. The additional power output will be fixed during $5 \mathrm{~s}$. Next, the power output will gradually decrease below the power output of the pre-disturbance level. The rotor speed reaches its lowest value at that moment and starts to accelerate back to the original value.

When this value is reached, the frequency controller is disabled and the MPT controller takes over the power control of the turbine. The results show that the frequency response is highly improved. The minimum frequency is even higher than in case A with no wind power integration. The main drawback of using this control however is the secondary frequency dip that arises when the wind turbine accelerates back to its optimal rotor speed.

\section{Frequency support by wind turbines in sub-optimal oper- ating point (Case E)}

Finally, the wind turbine will have a power margin available to deliver frequency support. The results of a frequency dip are shown in figure 14. Because the wind turbines deliver now both inertial response and primary control, the frequency response is higly improved. On the other hand, keeping reserves by wind power plants is relatively expensive due to production support mechanisms and negligible marginal costs. The results of all the cases are summarized in the appendix.

\section{INFLUENCE OF GENERATION MIX}

To study the influence of changing the generation mix in the power system, the test grid from Figure 1 is simplified. It is assumed that the load is always $500 \mathrm{MW}$ and the production units are now split up in hydraulic, thermal and wind. Both the wind speed as the distribution between thermal and hydraulic power plants are varied. The capacity of the wind power plant is $150 \mathrm{MW}$. To simulate a frequency dip, a power imbalance of $50 \mathrm{MW}$ is assumed. The results of this simulation are shown in Figure 15.

This figure shows the minimum frequency and the initial ROCOF in function of the wind speed and the generation mix. This generation mix is expressed as a percentage of the total produced power without wind energy included. If for instance the wind speed is $10 \mathrm{~m} / \mathrm{s}$ (which corresponds to 100 MW of wind power) and the distribution is $90 \%$ hydro and $10 \%$ thermal, the hydraulic turbines produce $360 \mathrm{MW}$ and the thermal power plants $40 \mathrm{MW}$. The wind turbines are equipped with a frequency controller to deliver an inertial response as described in section IV-C1.

It is clear that if the wind speed increases, the frequency response is deteriorated since the turbines only deliver an inertial response and not any primary control. Adding a frequency controller (for delivering inertial response) improves the frequency response until the wind speed reaches the rated wind speed. At this speed the turbines operate at rated power and no inertial response is delivered (assuming that 

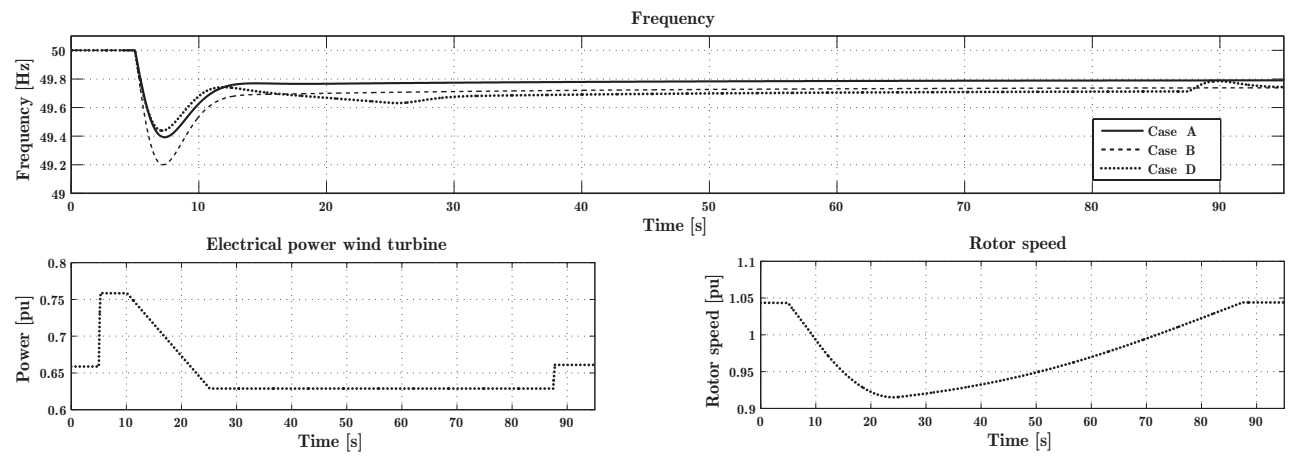

Fig. 13. Frequency response case A,B \& D

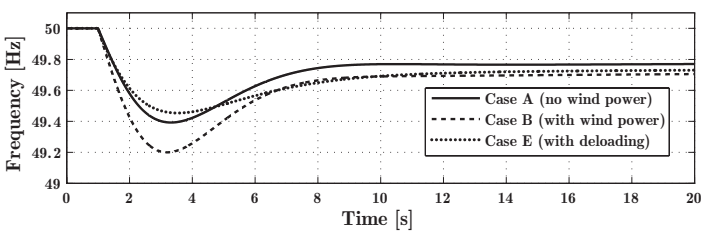

Fig. 14. Frequency response case A,B \& E

the converter limits the power to the rated power). Even more important is the influence of the generation mix. Due to the non-minimum phase behavior of the hydraulic turbines (initial power output is opposite to direction of change in gate position), it takes longer to stop the frequency decrease. Thus, if the share of hydraulic turbines in the generation mix is increased, the minimum frequency is lowered.

The ROCOF is rather independent of the generation mix, because the inertia of the hydraulic turbines is assumed to be the same as the inertia of the thermal power plant. From the ROCOF results, the effect of the frequency controller is very clear. Below rated wind speed, the ROCOF is increased by $0.1 \mathrm{~Hz} / \mathrm{s}$.

\section{CONCLUSION}

This paper studies the impact of wind power penetration on frequency stability and provides control mechanims to deliver frequency support and inertial response by wind turbines. The focus has been put on the variable speed wind turbine with DFIG.

The comparison between a grid with and without wind power shows that displacing conventional generation without additional measures will lead to a deterioration of the system frequency response after a power imbalance. This behavior is mainly caused by the electrical decoupling of the wind turbine from the grid, which leads to a smaller inertia from a grid point of view.

The frequency stability is improved significantly by integrating different types of frequency controllers in the turbine. The different methods were categorized based on the current operating point (optimal and sub-optimal). In the optimal operating point, the frequency control could only be delivered for a short time from the kinetic energy stored in the turbine and was restricted to some limitations like the converter and generator rating. However, the main advantage of this method is that no wind power is lost during normal operation. A closer look at the influence of the generation mix shows that especially in the case of a hydro dominated system, frequency control by wind turbines improves significantly the frequency stability. On the other hand, in deloaded operation, a sustained increase in power is achieved after an event. The frequency response is highly improved, but wind power is lost in normal operation.

Future research could be conducted to make clear if it is feasible in an economical way to deload a wind turbine. Real time wind speed measurements, electricity prices and unit commitment need to be combined to perform a technoeconomical analysis. It is also interesting to look for the possibilities to extend the control techniques to other renewable energy sources, like solar energy, tidal energy and wave energy.

\section{APPENDIX A}

TABLE I

PARAMETERS FOR EACH GENERATION UNIT

\begin{tabular}{lcccccc}
\hline & HT & ST1 & ST2 & ST3 & GT & WT \\
\hline Capacity [MW] & 110 & 120 & 140 & 150 & 80 & 150 \\
Dispatched power [MW] & & & & & & \\
$\quad$ Case A & 100 & 100 & 120 & 130 & 50 & $/$ \\
$\quad$ Case B-E & 100 & $/$ & 120 & 130 & 50 & 100 \\
Inertia constant [s] & 5 & 6 & 3.5 & 4 & 3 & $/$ \\
Droop [\%] & 5 & 5 & 5 & 5 & 5 & $/$ \\
\hline
\end{tabular}

\section{APPENDIX B}

TABLE II

OVERVIEW OF DIFFERENT CASES

\begin{tabular}{llll}
\hline & Description & $\begin{array}{l}\text { Mininum } \\
{[\mathrm{Hz}] \text { (dip) }}\end{array}$ & $\begin{array}{l}\text { Initial RO- } \\
\text { COF [Hz/s] } \\
\text { (dip) }\end{array}$ \\
\hline A & $\begin{array}{l}\text { Gen. mix as shown in table I } \\
\text { B }\end{array} \begin{array}{l}\text { Gen. mix as shown in table I, ST1 shut down } \\
\text { to absorb wind power }\end{array}$ & -49.37 & -0.51 \\
C $\quad \begin{array}{l}\text { Gen. mix equal to case B, optimal operating } \\
\text { point, emulating inertial response }\end{array}$ & 49.24 & -0.76 \\
D $\quad \begin{array}{l}\text { Gen. mix equal to case B, optimal operating } \\
\text { point, deliver fast kinetic energy injection }\end{array}$ & 49.72 & -0.48 \\
E $\begin{array}{l}\text { Gen. mix equal to case B, at sub-optimal } \\
\text { operating point, deliver inertial response + } \\
\text { primary control }\end{array}$ & 49.48 & -0.55 \\
\hline
\end{tabular}



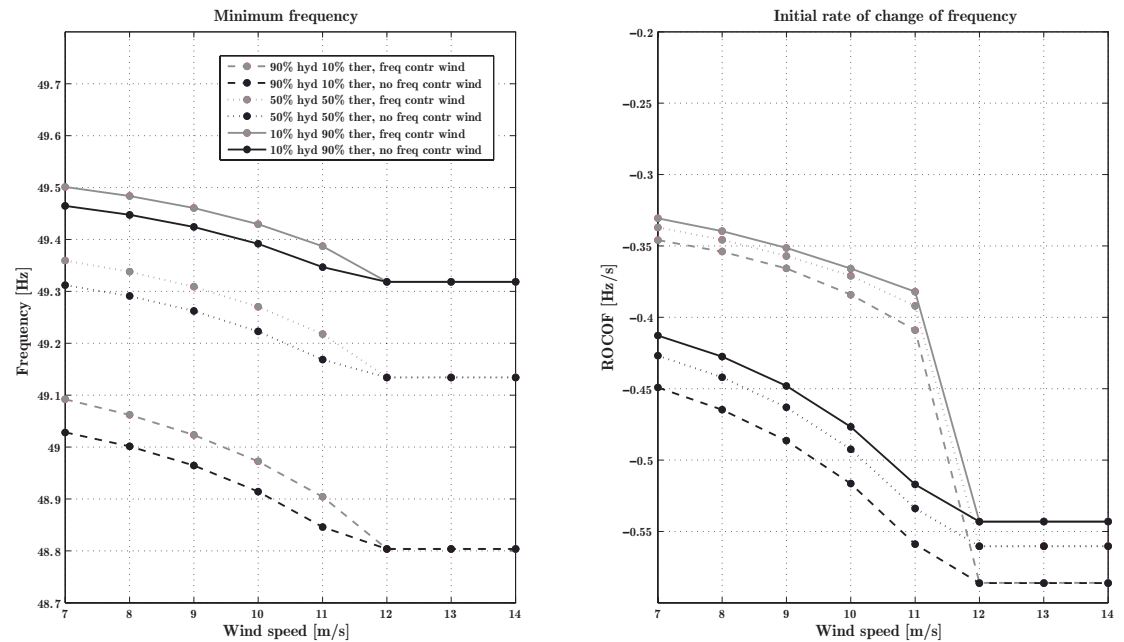

Fig. 15. Minimum frequency and ROCOF in function of the wind speed and generation mix

\section{REFERENCES}

[1] EWEA, "Powering Europe : wind energy and the electricity grid," 2010. [Online]. Available: www.ewea.org

[2] L. Meegahapola and D. Flynn, "Impact on transient and frequency stability for a power system at very high wind penetration," in Power and Energy Society General Meeting, 2010 IEEE, july 2010, pp. 1 -8.

[3] B. Fox et al., Wind Power Integration: connection and system opertional aspects. London, UK: The Institution of Engineering and Technology, 2007.

[4] A. Mullane and G. Bryans, "Kinetic energy and frequency response comparison for renewable generation systems," in International Conference on Future Power Systems, Amsterdam, 2005.

[5] J. Morren, J. Pierik, and S. De haan, "Inertial response of variable speed wind turbines," Electric Power Systems Research, vol. 76, no. 11, pp. 980-987, Jul. 2006

[6] M. Kayikci and J. Milanovic, "Dynamic Contribution of DFIG-Based Wind Plants to System Frequency Disturbances," IEEE Transactions on Power Systems, vol. 24, no. 2, pp. 859-867, May 2009.

[7] A. Perdana, "Dynamic models of wind turbines: a contribution towards the establishment of standardized models of wind turbines for power system stability studies," PhD dissertation, Chalmers university of technology, Sweden, 2008.

[8] A. Hansen, C. Jauch, P. Sørensen, F. Iov, and F. Blaabjerg, "Dynamic wind turbine models in power system simulation tool DIgSILENT," RisøNational Laboratory, Tech. Rep. August, 2007. [Online]. Available: http://www.digsilent.de/Software/Application_Examples/ris-r-1400.pdf

[9] P. Kundur, Power System Stability and Control. New York, US: McGraw-Hill, 1994.

[10] J. Ekanayake, N. Jenkins, and G. Strbac, "Frequency Response From Wind Turbines," Wind Engineering, vol. 32, no. 6, pp. 573-586, Dec. 2008

[11] O. I. Elgerd, Electric energy systems theory: an introduction. New Delhi, India: Mc Graw Hill, 1982.

[12] J. F. Conroy and R. Watson, "Frequency Response Capability of Full Converter Wind Turbine Generators in Comparison to Conventional Generation," IEEE Transactions on Power Systems, vol. 23, no. 2, pp. 649-656, May 2008.

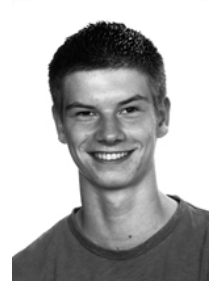

Pieter Tielens (S'11) was born in Belgium in 1988 He received the M.Sc. degree in electrical energy engineering from the Katholieke Universiteit Leuven (K.U.Leuven), Leuven, Belgium, in 2011, where he is currently working towards a Ph.D. degree. He is a Research Assistant in the research group ELECTA, department of Electrical Engineering of the K.U.Leuven. His fields of interest are the integration of renewable energy resources into the electricity system and inertialess grids.

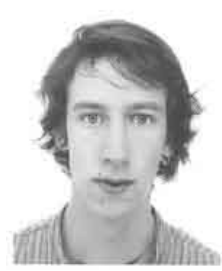

Simon De Rijcke (S'08) was born in Belgium, on May 26, 1986. He graduated as an electrotechnical engineer from the K.U.Leuven in 2009 and received a master of science in energy. Since 2009 he is working as a research assistant towards a Ph.D. in the research group ELECTA, department of Electrical Engineering of the K.U.Leuven. His research interests are power system operation with the integration of renewable energy sources.

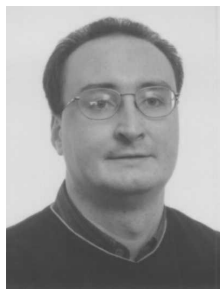

Johan Driesen (S'93-M'97) was born in 1973 in Belgium. He received the M.Sc. degree in 1996 as Electrotechnical Engineer from the K.U. Leuven, Belgium. He received the Ph.D. degree in Electrical Engineering at K.U.Leuven in 2000 on the finite element solution of coupled thermalelectromagnetic problems and related applications in electrical machines and drives, microsystems and power quality issues. Currently he is a professor at the K.U.Leuven and teaches power electronics and drives. In 20002001 he was a visiting researcher in the Imperia College of Science, Technology and Medicine, London, UK. In 2002 he was working at the University of California, Berkeley, USA. Currently he conducts research on distributed generation, including renewable energy systems, power electronics and its applications, for instance in drives and power quality. 


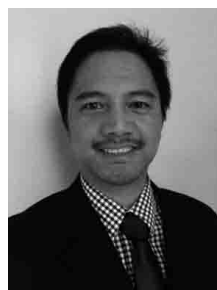

Muhamad Reza did his Bachelor in Bandung Institute of Technology, Indonesia and obtained his MSc and $\mathrm{PhD}$ in Power Systems from Delft University of Technology, the Netherlands. He was a research assistant in Bandung Institute of Technology, Indonesia in 2000-2002. In 2006 after completion of his PhD he joined ABB Corporate Research Sweden, where he has been working as scientist and project leader in different areas of power systems including grid integration wind energy. Currently he is the coordinator of $\mathrm{ABB}$ global wind technology team.

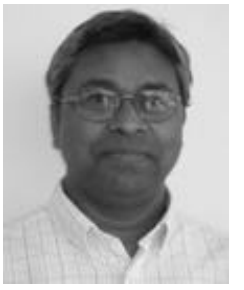

Kailash Srivastava (SM'96) was born at Fatehpur in India, on October 3, 1962. He graduated in Electrical Engineering from MMM Engineering College Gorakhpur (India) in 1983. He did his MTech and $\mathrm{PhD}$ in Power Systems from IIT Kanpur (India) in 1986 and 1995 respectively. His research interests include power system dynamics, control, hvdc, optimisation techniques, modeling and simulation of power systems. He has been working for ABB since April 1997.

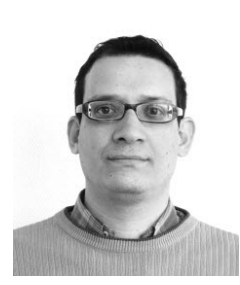

Antonis Marinopoulos was born in Thessaloniki, Greece. He received his Dipl.-Eng. degree in 2003 and the Ph.D. degree in 2009, both from the Department of Electrical and Computer Engineering at the Aristotle University of Thessaloniki, Greece. Since 2010, he has been with ABB Corporate Research Sweden, working as a researcher in various projects in different power systems areas. His research interests are in the field of power system analysis and simulation, power system integration of renewable energy sources, and distributed generation.

Copyright (C)2012 IEEE. Personal use is permitted. For any other purposes, permission must be obtained from the IEEE by emailing pubs-permissions@ieee.org. 